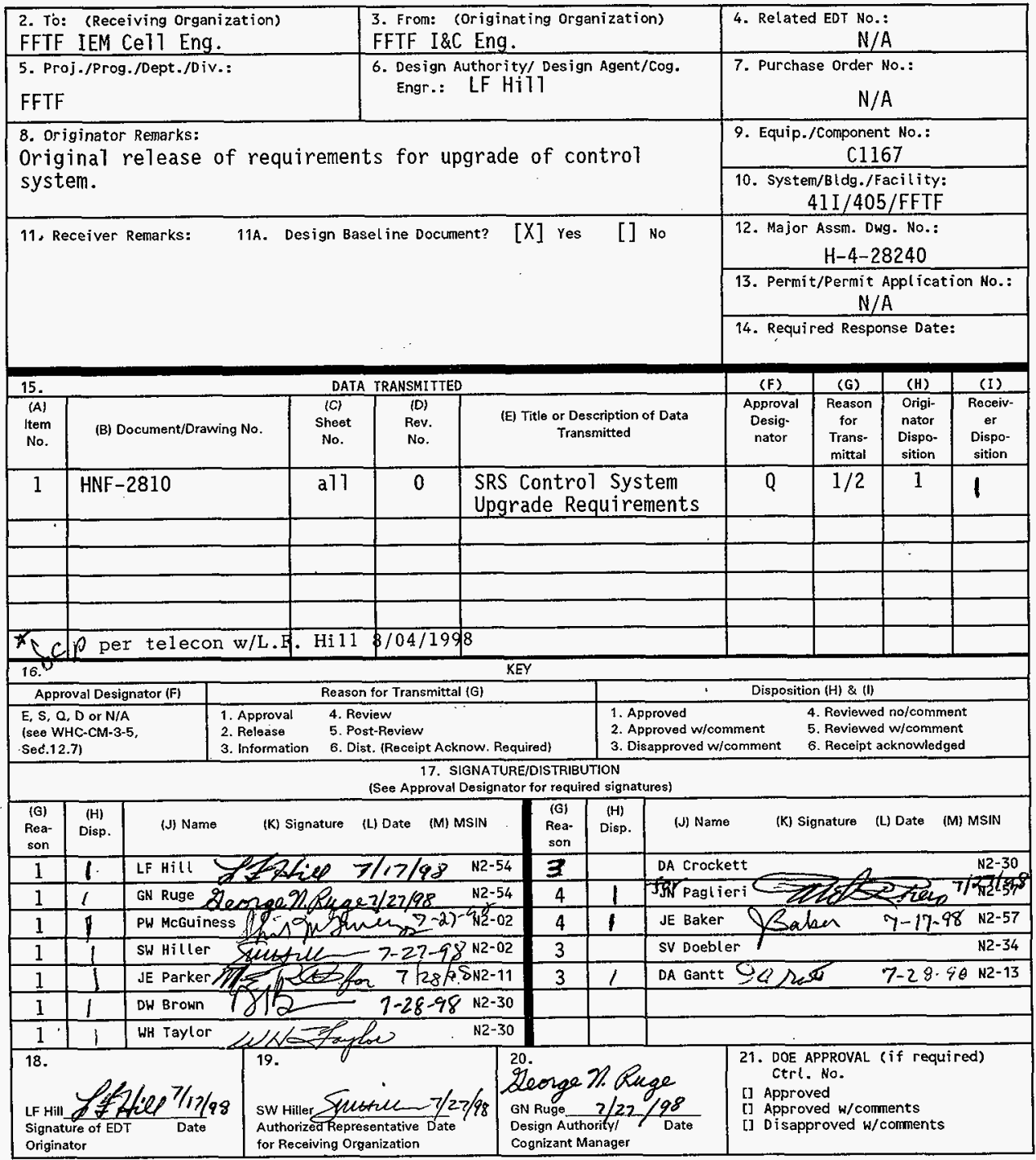

BD-7400-172-2 (05/96) GEF097 


\section{SRS Control System Upgrade Requirements}

\section{F. Hill}

FFTF Project

Richland, WA 99352

U.S. Department of Energy Contract DE-AC06-96RL13200

EDT/ECN: 619623

Org Code: 18250

B\&R Code: EX7050000

UC: 541

Charge Code: B1258

Total Pages: 201

Key Words: FFTF, IEMC, IEM Cel1, SRS, Control, Upgrade, C1167 Sodium Removal System

Abstract: Defines requirements for upgrading the control system for the Sodium Removal system to address maintenance and life problems, and to improve the ergonomics of the operator interface.

TRADEMARK DISCLAIMER. Reference herein to any specific commercial product, process, or service by trade name, trademark, manufacturer, or otherwise, does not necessarily constitute or imply its endorsement, recommendation, or favoring by the United States Government or any agency thereof or its contractors or subcontractors.

Printed in the United States of America. To obtain copies of this document, contact: Document Control Services, P.O. Box 950, Mailstop H6-08, Richland WA 99352, Phone (509) 372-2420; Fax (509) 376-4989.

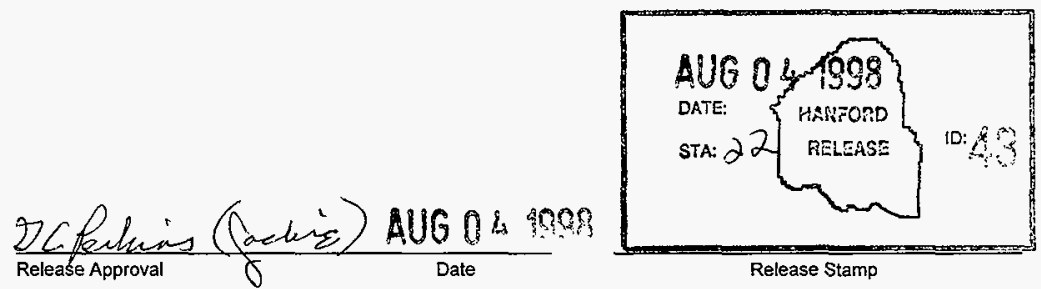

\section{Approved For Public Release}




\section{RELEASE AUTHORIZATION}

Document HNF-2810, Rev. 0
Number:

\section{Document}

Title:

\section{This document, reviewed in accordance with DOE Order 1430.1D, "Scientific and Technical Information Management," and DOE G 1430.1D-1, "Guide to the Management of Scientific and Technical Information," does not contain classified or sensitive unclassified information and is:}

\section{APPROVED FOR PUBLIC RELEASE}

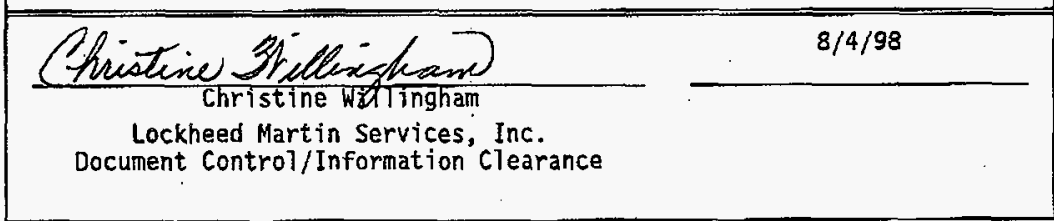

Reviewed for Applied Technolosy, Business Sensitjve, Classified, Copyríghted, Export Controlled, Patent, Personal/Priyaze, Proprietary, Protected CRADA, Trademark, Unelassified Contralled Nuclear Information.

LEGAL DISCLAIMER. This report was prepared as an account of work sponsored by an agency of the Unitred States Government. Neither the United States Government nor any agency thereof, not any of their employees, nor any of their contractors, subeoneractors or their employees, makes any warranty, express or implifed, or assumes any legal liability or responsibility for the accuracy, completeness, or any third party's use or the results of sueh usc of any information, apparatus, product, or process disclosed, or represents that its use would not infringe privatoly awned rights. Reference herein to any specific commercial product, prosess, or service by trade name, tradenark, manufacturer, or otherwise, does not necessarily constiture or imply its endarsenent, recomendation, or favoring by the United states Govermment or any agency thereof or its contractors or subcontractors. The views and opinions of authors expressed herein do not necessarily state or reflect those of the United States tovernment or any agency thereof. This report has been reproduced fron the best available copy. Printed in the Unired States of Anerite. Available to the U.S. Department of Energy and its contractors from the U.S. Department of Energy Office of scientific and Technieal Information, P.0. Box 62, Oak Ridge, TN 37831; Velephone: 623/576-8401.

Available to the public fren the U.S. Deparement of Commerce National Technical Information Service, 5285 Port Royal Road, Springfield, VA 22161; Telephone: 703/487*4650, 
1.1 General Description of Existing Control System 1

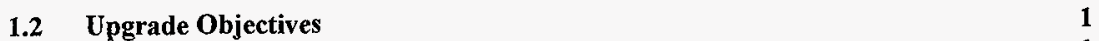

1.2.1 Extend System Life 1

1.2.2 Resolve Access Restrictions

1.2.3 Improve Isolation of Power Sources $\quad 2$

1.2.4 Improve Human Factors of Operation $\quad 2$

1.2.5 Provide Emergency Control Panel 2

$\begin{array}{ll}1.3 & \text { Description of Upgrade }\end{array}$

1.4 Interfaces $\quad 3$

1.4.1 Containment Isolation Valves (CIS) Valves 3

1.4.2 Field Wiring $\quad 3$

1.4.3 Emergency Transfer Switch

1.4.4 Console Location $\quad 4$

2.0 FUNCTIONAL REQUIREMENTS

2.1 Operator Interface $\quad 4$

2.1.1 Overview Graphic $\quad 4$

2.1.2 Detailed Process Graphics $\quad 4$

2.1.3 Control Popup Screens $\quad 5$

2.1.4 Screen Representations 5

2.1.5 Screen Standards $\quad 5$

2.2 Enhanced Functionality $\quad 5$

2.2.1 Valve Lineup Macros $\quad 5$

2.2.1.1 Mode Indications $\quad 5$

2.2.1.2 Valve Macros $\quad 5$

2.2.1.3 Macro Permissives $\quad 6$

2.2.2 Auto Controls $\quad 6$

2.2.2.1 Tank Pressure Controls

2.2.2.2 Tank Vent Controls $\quad 7$

2.2.2.3 Timed Condensate Drains.

2.2.2.4 Pre-cooler Temperature $\quad 7$

2.2.3 Trend/History Displays $\quad 7$

2.2.4 Water Inventory _ . 7

2.2.4.1 Linear Level Readings $\quad 7$

$\begin{array}{lll}2.2 .4 .2 & \text { Water Inventory } & 8\end{array}$

2.2.4.3 Transfer Counters $\quad 8$

$\begin{array}{lll}2.2 .5 & \text { Dry Indication } & 8\end{array}$

2.2.6 Relief Valve Monitoring $\quad 8$ 


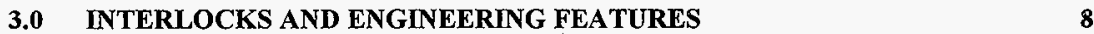

$\begin{array}{llr}3.1 & \text { Power Isolation } & 8\end{array}$

$\begin{array}{llr}3.2 & \text { Emergency Control Panel } & 9\end{array}$

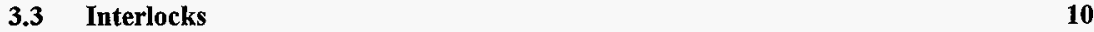

3.3.1 Existing Interlocks $\quad 10$

$\begin{array}{ll}\text { 3.3.2 Existing Alarms } & 10\end{array}$

$\begin{array}{ll}\text { 3.3.3 New Interlocks \& Alarms } & 10\end{array}$

$\begin{array}{lll}3.4 & \text { Simulator } & 11\end{array}$

$\begin{array}{llr}3.5 & \text { Security } & 11\end{array}$

$\begin{array}{ll}\text { 3.6 Power Outage and Restoration } & 12\end{array}$

$\begin{array}{ll}4.0 & 12\end{array}$

$\begin{array}{llr}\text { 4.1 Safety Class } & 12\end{array}$

4.2 Documentation $\quad 12$

4.2.1 Drawings 12

4.2.2 Software Design Description $\quad 12$

4.2.3 Software Configuration Management Plan $\quad 12$

4.2.4 Operating Procedures $\quad 12$

4.2.5 FSAR Revision $\quad 13$

$\begin{array}{lll}4.3 & \text { Testing } & 13\end{array}$

4.3.1 Verification Tests $\quad 13$

4.3.2 Calibration, Grooming, and Alignment 13

4.3.3 Validation Tests $\quad 13$

$\begin{array}{lll}4.3 .4 & \text { Mini-ATP } & 13\end{array}$

4.4 Training 13

$\begin{array}{lll}4.5 & \text { Spares } & 14\end{array}$

$\begin{array}{llr}\text { 4.6 Y2K Compliance } & 14\end{array}$

$\begin{array}{llr}\text { 5.0 REFERENCES } & 14\end{array}$

$\begin{array}{lr}\text { ATTACHMENT A: EXISTING SRS INTERLOCKS } & 15\end{array}$ 


\section{SRS Control System \\ Upgrade Requirements}

\subsection{SCOPE}

This document defines requirements for an upgrade of the Sodium Removal System (SRS) control system. The upgrade is being performed to solve a number of maintainability and operability issues. The upgraded system will provide the same functions, controls and interlocks as the present system, and in addition provide enhanced functionality in areas discussed in this document.

\subsection{General Description of Existing Control System}

The existing SRS control system is a manual hardwired system, which was installed during the initial Fast Flux Test Facility (FFTF) construction. Most all of the valves and instruments are wired back to a four-bay panel on the second level of the Interim Examination and Maintenance (IEM) Cell gallery (panel C1167). On the back panel (interior) of $\mathrm{C} 1167$ are terminal boards for landing the field wires, relays for interlocks, and a few other miscellaneous components. The front of $\mathrm{C} 1167$ has a large number of switches and indicators for control of each individual valve, motor or other device. The layout of the switches is patterned after the Piping and Instrumentation Diagram (P\&ID), with colored tape to define the flow paths and valve locations. This provides a pictorial representation (mimic), which improves the ability of the operator to associate each switch with the process. The front panel is fixed in place and is about two feet out from the back. The only access to the internals is via a door on the left end. Additional details of the system are given on the drawings noted in Section 1.4.

\subsection{Upgrade Objectives}

The objectives discussed in this section address the primary problems that need to be corrected. Resolution of these issues is required for a long-term FFTF mission, but they also address real needs relative to keeping the system operational for the remainder of the fuel washing required to proceed with the shutdown option.

\subsubsection{Extend System Life}

A number of components are experiencing wear-out. The strip chart recorder has failed and is not repairable or directly replaceable. Current technology would utilize a computer-based solution as a replacement. The control switches are intermittent and sometimes have to be "jiggled" to work properly - some refurbishment has been done but the problem can be expected to continue. The relays have been fairly reliable, although there have been problems in the adjustment and stability of the many "time-delay" relays. Also, since the relays are mounted horizontally, their plungers have exhibited a tendency to "stick," which will worsen with wear. In summary, the upgrade should address enhancing the maintainability and life of the hardware. 
HNF-2810, Revision 0

\subsubsection{Resolve Access Restrictions}

To electrically troubleshoot or work on any of the equipment requires getting inside of the panel via the single door on the end. With exposed wiring on front and back, this does not meet the National Electric Code requirements for working access (Section 110-16 requires three feet of clearance). This significantly complicates maintenance, and the upgrade should address removing this restriction.

\subsubsection{Improve Isolation of Power Sources}

As a further complication to the restricted access identified above, the panel is powered from 12 power sources, including several emergency buses. Thus, isolating the panel for work is time-consuming and causes increased concerns due to the many power sources. While the multiple power sources cannot be combined, the upgrade should provide separation and isolation within the panel to improve the ability to verify the status of each power source.

\subsubsection{Improve Human Factors of Operation}

There are a number of ergonomic problems with the current panel, which should be addressed in the upgrade. The front panel layout, being only a "dead mimic," does not provide a simple indication of what general operation (e.g., mode) is presently being performed, nor provide any assistance to the operator in verifying that all valves are setup appropriately for the current mode. Many of the analog displays have significant parallax problems so that they cannot be reliably read to the desired accuracy. Many of the controls could be better grouped to provide more consistent operation. Details of the operational enhancements are discussed further in later sections.

\subsubsection{Provide Emergency Control Panel}

The existing emergency control panel is of limited utility to provide a backup to the main controls. While it provides backup control switches for some functions, it does not provide control of other valves which would also be needed to establish the full flow path. The upgrade should provide a backup (redundant) method to actuate the appropriate valves, blowers, and pumps to establish emergency cooling consistent with the Final Safety Analysis Report (FSAR) requirements.

\subsection{Description of Upgrade}

In consideration of the above upgrade objectives, it is clear that the $\mathrm{C}-1167$ panel must be significantly reworked to provide safe electrical access. This is consistent with the need to rework or replace the front panel to improve ergonomic factors. It seems clear then, that the upgrade should move the controls off of the front panel onto a computer/Cathode-ray tube (CRT) based system, which is the modern solution for this type of control system. This would replace 
the switches and relays with solid-state controls (no moving parts to wear out) and free up the front to be used as doors for improved access. The strip chart recording function would become a general trending capability for any channel(s).

The overall features of the upgraded system are as follows. The front panel will be replaced with doors for access to the panel interior. The doors will likely house a few displays and switches for the emergency control functions, but they will not interfere with access. The terminal boards on the back panel will be replaced with $\mathrm{I} / \mathrm{O}$ modules for connecting the field wires to the computer. Except for a few essential hardwired interlocks, most of the relays will be replaced by computer-based logic so that overall, there will be less hardware on the back panel. The computer will likely be housed in the cabinet. To save space, the CRT could be mounted in the door, but to achieve a better ergonomic arrangement will probably be located on a table at the end (where the existing teletype is located). This allows providing a workstation at the proper height, a supportive chair and a small work area.

A set of screens and controls will be provided for the CRT display, which will allow the operator to control the system in the same manner as at present. The system will still function as described in the FSAR - as a "manually operated process" with some "interlocks to assist the operator." While the operator will still directly command each valve or fan change, some enhanced functionality will be provided, such as the capability to switch several (related) valves with a single command. Live (mimic) displays will be provided to show the current system status and simplify valve lineups when switching between modes, as well as to improve diagnostic and maintenance activities. Improved alarming capabilities will better inform the operator of system problems.

\subsection{Interfaces}

\subsubsection{Containment Isolation Valves (CIS) Vaives}

The CIS valves will be controlled from the Control Room in the same manner as at present. The current feedback signal, a single "all closed" summation, will be used to portray all the CIS valves on the SRS graphics.

\subsubsection{Field Wiring}

No changes are anticipated to field wiring coming into panel $\mathrm{C} 1167$, except that they will land on terminals with different numbering, which will require some drawing changes to interfacing systems.

\subsubsection{Emergency Transfer Switch}

The new Emergency Controls are not expected to utilize the existing Emergency Transfer Switch box. However, it is not planned to rework the box, but to simply leave the switch set to the normal "straight-through" position so that the signals continue to pass through the box. If desired, a separate package could be prepared to replace the switch with a terminal strip. 


\subsubsection{Console Location}

The new operator console shall be located in the vicinity of the $\mathrm{C}-1167$ panel, and shall not interfere with access to the adjacent IEM Cell windows ( $2 \mathrm{~B}$ and $2 \mathrm{C}$ ).

\subsection{FUNCTIONAL REQUIREMENTS}

Operator monitoring and control shall support being able to control the system in the same manner as the present system, and also provide enhanced functions as described in this section. The functional requirements are written with the assumption that the upgraded operator interface will be CRT based.

\subsection{Operator Interface}

An inter-related set of graphics shall provide monitoring and control of the system. An overview graphic shall show overall process status and provide access to more detailed process graphics. The detailed process graphics shall depict the process in a manner similar to the P\&ID (in sections), and shall be organized to correspond to the functional operating modes. Additional graphics shall provide access to alarms, valve controls, trending and other miscellaneous functions. To facilitate access to different features of the system, the design shall allow the user to simultaneously display at least two graphics, as desired, from among the total set.

\subsubsection{Overview Graphic}

- The overview graphic shall show the overall status of the system and provide direct navigation to all other process graphics. The active mode shall be indicated, as well as any currently open flow paths. Alarms shall be indicated on the overview graphic, as well as indication of which detailed graphic provides more detail about the alarm.

\subsubsection{Detailed Process Graphics}

These are the primary views that shall be used to monitor and control each stage of the washing process. They shall focus on the current operation, and may omit or summarize unnecessary equipment. Several graphics are anticipated to provide effective display for the various operational modes, some of which are listed below. A single graphic may provide display for - multiple modes. The final arrangement will be worked out with operations.

- Moist Gas Injection Mode

- Water Fill Mode

- Wash Mode

- Drain Mode

- Drying Mode

- Ion Exchange Mode

- System Pressure Test Mode(s) 


\subsubsection{Control Popup Screens}

Control of individual valves or devices shall be accomplished by selecting the desired valve, which shall display a "pop-up" window, from which the valve can be operated. To prevent inadvertent changes, all process changes shall require at least two operator actions. Where interlocks prevent valve operation under certain conditions, the applicable operator controls shall be "darkened" to clarify when the control is not available to the operator.

\subsubsection{Screen Representations}

Different portions of the process shall be shown in different colors to clarify the use. Each color shall be used for one and only one purpose. Open/close status of individual valves shall be shown, as well as the status of interconnecting lines (based upon valve statuses). This will result in highlighting current active paths. In addition, any available information about quantity of flow (e.g., pressure differences) shall be displayed.

\subsubsection{Screen Standards}

Screen designs shall be consistent with the guidelines of DOE6430.1A and NUREG-700.

\subsection{Enhanced Functionality}

\subsubsection{Valve Lineup Macros}

Provisions shall be made to facilitate valve lineups and provide better feedback regarding the overall function being performed based on the current lineup. New "macros" will be provided to operate a (predetermined) set of valves when commanded by the operator. Feedback of the current lineup will be enhanced by logically combining the status of multiple valves into new "mode" indications. Details of specific macros and indicators will be developed and approved during the design.

\subsubsection{Mode Indications}

The overall wash cycle progresses through a series of steps which can be considered "modes" - for example, moist gas injection, fill, recirculation, drain, drying and ion exchange. The intent is to logically assess the valve lineup and provide the operator with a single overall mode indication, with possibly some sub-modes. By letting the computer logically "sum the valve positions," the operator can more reliably assess the system status.

\subsubsection{Valve Macros}

A valve macro is essentially a list of valve commands, which is executed (once) when commanded by the operator. This allows setting a group of valves to predetermined positions, either simultaneously or sequentially. It is desirable to generally align the 
macros with the modes discussed above - in other words, provide a macro to directly select each mode or sub-mode. Thus, selecting a mode button would move the appropriate valves into proper alignment and the mode indicator would confirm the proper lineup. Additional macros may be effective for valve adjustments within a primary mode. The objective is to promote a more functional operational interface, whereby the operator selects a function to perform rather than opening and closing a list of valves. This allows the operator to be more aware of overall system operation. It should be noted that there is no intent to actually start an operation via the macros, only to perform the valve lineup in preparation for starting. The operator will initiate operation (e.g., start the fan) after confirming that all conditions are proper for that mode.

\subsubsection{Macro Permissives}

Provisions shall be included to prevent inappropriate use of the macros. Specifically, each macro shall require that certain initial conditions must be satisfied before the macro can be invoked.

\subsubsection{Auto Controls}

In a few cases, the previous control system placed the operator in a "servo loop," where they were actively operating valves to maintain certain process conditions. Since computers are better than operators at this type of task, some additional automation will be added so that the operator can be freed to better monitor and control the overall system. Auto controls will allow the operator to specify a setpoint for certain parameters, and the control system will then automatically open/close the valve to achieve the desired value. Manual control of these valves shall still be available.

\subsubsection{Tank Pressure Controls}

Auto controls shall be provided on the Argon supply valve for each tank to maintain a specified pressure range in the tank:

- T100 - Operate HV-161 to increase PI-163 to setpoint.

- T101 - Operate HV-175 to increase PI-101 to setpoint.

- T102 - Operate HV-181 to increase PI-130 to setpoint.

Note that this control will only correct underpressure, because the vent valves may not be opened. However, when in the auto mode, alarms shall be provided for both overpressure and underpressure. A deadband range shall be selectable for each valve to limit excessive cycling of the valve. Other restrictions should also be considered if the deadband alone is not sufficient to prevent the valves from excessive cycling. 


\subsubsection{Tank Vent Controls}

Auto controls shall be provided for venting T101 and T102 when the vent is open. A macro is envisioned to facilitate the frequent need to switch to the "back side" to open the vent path - for example, closing HV-408 and HV-215, and opening HV-626 and HV-159. The backside being open to vent is a permissive to allow auto control of the "vent pressure" of these tanks.

- T101 - Operate HV-675 to reduce PI-101 to setpoint.

- T102 - Operate HV-681/685 to reduce PI-130 to setpoint.

\subsubsection{Timed Condensate Drains.}

As for the Tank Vent Controls, the backside being open to vent is a permissive for the condensate drain functions. When open to vent, timed operation of the each condensate drain valve shall be provided. When commanded, the drain valve shall open for a prescribed time and then close. The drain time shall be adjustable within limits.

- Blower - Open HV-627 to drain the blower.

- Purge Cooler - Open HV-608 to drain the purge cooler.

- Separator - Open HV-641 to drain the separator.

- Filter - Open HV-625 to drain the filter.

\subsubsection{Pre-cooler Temperature}

Provide auto temperature control on HV44 based upon TE-043 inlet to blower. Watch/ alarm blower temp inlet to avoid over-temperature on blower. Also may want to servo on TE-040.

Note: This capability to increase cooling of the Argon loop may not be needed if high heat assemblies are not required.

\subsubsection{Trend/History Displays}

Provisions shall be included to provide real-time and current trending of all analog value(s) in the system. Further discussions shall identify which parameters are appropriate for historical recording. Provisions shall also be included to print any trend display.

\subsubsection{Water Inventory}

\subsubsection{Linear Level Readings}

Provide EUC conversions for the tank level readings so they readout in gallons rather than linear height. 
HNF-2810, Revision 0

\subsubsection{Water Inventory}

Provide calculated estimates for the water inventory in T100. Also provide calculated sum of water in the system.

\subsubsection{Transfer Counters}

Provide two operator re-settable counters to monitor gallons transferred out of T101. Two counters are indicated to assist in keeping track of the quantity for each wash as well as the total for all washes.

\subsubsection{Dry Indication}

Efforts shall be made to provide a more repeatable dry cycle, which shall provide a clearer and more reliable indication of when the system is dry. An optional timed operation of the back loop during drying shall be provided.

\subsubsection{Relief Valve Monitoring}

Provisions shall be included to facilitate monitoring of the status of the T101 and T102 relief valves. Though they are not explicitly instrumented, their opening would be apparent if tank pressure were being viewed at the time of opening. To improve visibility and cognizance of the relief valves, they shall be shown on the system graphics, and an alarm shall be generated when tank pressure reaches the relief setpoint. The alarm response can then instruct the operator to examine the trend display for possible opening of the relief valve.

\subsection{INTERLOCKS AND ENGINEERING FEATURES}

\subsection{Power Isolation}

The redesign shall attempt to group the power sources in the cabinet, and provide either deadfront terminations and/or local isolation for each power source. It is recognized that this may be somewhat hampered by existing wire routings and lengths which would be unreasonable to change within the existing scope.

Grouping and control of power sources has two objectives. First and foremost is to provide safe access for maintenance. A secondary objective is to assist in system alignment during offnormal conditions; de-energizing portions of the system can be operationally used to ensure the system is in the pre-determined power-OFF state. 


\subsection{Emergency Control Panel}

In anticipation of computer based control, a backup capability shall be provided to allow expeditiously configuring the system to a safe condition in the event of a failure of the primary computer control system. Provisions shall be included to operate the appropriate valves to restart Argon recirculation or to perform water flooding. The necessary changes shall be capable of being made within ten minutes.

. The following functions currently on the emergency panel are required (power source is given in parenthesis):

- HV-020 Clamp Open/Close (MV) and status indication (H1)

- HV-141 Open (SV) (DC)

- P128 On/Off \& status indication (B28)

- HV-3 Open/Close (MV) and status indication (H3)

- HV-4 Open/Close (MV) and status indication (H4)

- Blower1 Off/Slow/Fast and status indication (B14)

- Blower2 Off/Slow/Fast and status indication (B16)

- In addition, the following indications and controls (which are not on the current emergency panel) may also be required. Final arrangement shall be agreed upon between operations and engineering:

- PI-128, Pump outlet pressure

- LI-130, T102 level

- PI-021, T100 pressure

- FI-009, Blower flow

- TE-019, T100 temperature

- TE-003, Blower outlet temperature

- PI-002 and PI-003, Blower inlet/outlet temperatures

For water addition, would need to assure the following are open:

- HV-019, T100 Top Outlet and status (H1)

- HV-024, T100 Bot Inlet and status (H1)

- HV-129, Clean Station Water return and status (H2)

- HV-145, Rinse drain and status (H5)

... and assure the following are closed:

- HV-113, Blower bypass (need reset PB) and status (H5)

- HV-023, T100 Top Inlet and status (Breaker OFF) (H1)

- HV-619, T100 Drain and status (Breaker OFF) (H5) 
For water transfer from T101->T102, would need:

- HV-159, CAPS vent and status (DC)

- HV-681/5, T102 Vent (DC)

- HV-175, T101 Argon Supply (DC)

- HV-401, Argon header supply (fails open) and status (H5)

- HV-626, System Vent to CAPS (DC)

- HV-601, Open/Close control (DC)

- HV-602, Open/Close control (H1)

\subsection{Interlocks}

\subsubsection{Existing Interlocks}

The existing interlocks as described in Attachment $\mathrm{A}$ shall be retained and enforced by the computer logic. However, the new design will also provide other methods of enforcing the interlocks, which can serve as a backup if the computer fails. Interlocks can be enforced in the following ways:

- Software Implemented within software in the computer

- Hardware Implemented by relay logic (computer independent)

- Emergency Panel (administrative) for devices on Emergency Panel.

- Power Isolation (administrative) force valve to its de-energized state

The interlock list was reviewed to ascertain that the critical interlocks have a backup in the event of computer failure. Attachment A identifies which of the above methods will be used to provide each interlock.

\subsubsection{Existing Alarms}

The existing alarms shown on the P\&ID (H-4-28240) and Schematic (H-4-28233) shall be retained, and the setpoints shall be the same unless subsequent analysis determines that different setpoints and/or tiered alarms would be preferable. The alarms may be in software, unless a hardware (HW) alarm is required to support the interlock implementation discussed in the previous section and Attachment $\mathrm{A}$.

\subsubsection{New Interlocks \& Alarms}

The following new interlocks and/or alarms shall be provided.

- Motorized Valves Timing. Ensure the normal operation of the Motor Controlled Valves utilizes a "time-delay" so that the operator does not have to be concerned about leaving switches on for specified times. This basically duplicates the function of the existing time-delay relays. 
- Dome Clamp Timing. Ensure dome clamps are run to full open prior to closing, even when they are stopped in mid stroke. Since there is only an OPEN limit switch, proper timing of the close operation is essential to ensure the clamps are CLAMPED.

- Depressurization Warning. Warn the operator if T100, T101, and T102 are not depressurized prior to opening the Dome clamps.

- Water Supply. Warn the operator if either the demin water supply (HV-101) or the Ion Exchange return (HV-601) are opened when the CIS valves are open.

- Argon Blowers Temp Limit. Add a high alarm at argon blower inlet temperature of $122^{\circ} \mathrm{F}$ (TI-043).

- T101 Temperature. Provide an over-temperature alarm on T101 temperature, based upon TI-101.

- Water Inventory. Provide high and high-high limits on the total water inventory to monitor the status relative to the FSAR criticality limits.

Since all analog channels will be available to the computer, the system shall provide for subsequent addition of low/high alarms to any channel. Such alarms could be added to assist the operator in monitoring system status.

In addition to the above process-related alarms, various control system alarms shall also be - provided for situations where (for some reason) operator commanded actions can not actually be completed. For example, an alarm should be generated if an operator command to OPEN a valve does not result in the valve limit switch(s) showing OPEN within the prescribed operating time. This type of control alarms should generally be at a lower priority than process related alarms.

\subsection{Simulator}

The control system shall include a simulation mode, in which the operator controls can be exercised without operating the process. Simulation mode will be used for system verification during development and maintenance, and for operator training. The process simulation shall include the capability to operate valves, pumps and motors, and to observe appropriate responses in system pressures, flows and temperatures.

\subsection{Security}

Key-switch and/or password controls shall be provided for limiting access to the control system. A single access account shall be provided for all qualified operators. This account will provide full access to all monitoring and control functions.

Provisions shali also be included for a "monitor-only" capability. In this mode, all system status shall be available for monitoring but access to control functions is prevented. 


\subsection{Power Outage and Restoration}

The overall system design shall provide controlled responses to loss of power and power restoration. Upon loss of power, devices not on emergency power will (obviously) switch to their de-energized state, and the control system may make other predetermined changes, as determined necessary to place the system in a safe condition. Power restoration, in general, shall not actuate any devices but rather leave them in their "de-energized" condition - unless it is determined that certain devices should be automatically actuated.

\subsection{UPGRADE LOGISTICS}

Miscellaneous issues involved in performing the upgrade.

\subsection{Safety Class}

The control system is Safety Class 4 (or General Service), but must continue to meet the "three over one" criteria, which is to not adversely affect any Class 1 equipment.

\subsection{Documentation}

\subsubsection{Drawings}

Updated/revised hardware assembly and electrical/wiring drawings for the $\mathrm{C} 1167$ panel shall be provided. Loop diagrams and Logic diagrams shall also be provided, but may be released in an alternate form, such as SD's or electronic drawing files.

\subsubsection{Software Design Description}

A Software Design Description shall be generated to describe the design and implementation of the software.

\subsubsection{Software Configuration Management Plan}

A Software Configuration Management Plan shall be generated to define the methodology to be used to maintain the software. Configuration management shall be in place prior to the final verification tests.

\subsubsection{Operating Procedures}

Since full manual capability is being retained, the system is expected to be capable of being operated using the existing operating procedures, with only minimal instructions regarding how to use the CRT/mouse to operate valves rather then the existing switches. Revisions to the operating procedures will be required to make use of the enhanced functionality. 


\subsubsection{FSAR Revision}

From a preliminary review, these changes are not expected to result in any change to the FSAR. The Unresolved Safety Question Evaluation for the changes will document this and/or any necessary changes will be made.

\subsection{Testing}

\subsubsection{Verification Tests}

The operator screens and controls shall be "prototyped" and made available for operator evaluation and training prior to implementation in the facility. Verification testing using this configuration shall also be performed to qualify the operator screens and controls using the builtin simulator.

\subsubsection{Calibration, Grooming, and Alignment}

Following installation in the facility, a period of calibration, grooming, and alignment (CG\&A) will be required to ascertain that each $\mathrm{V} / \mathrm{O}$ channel is properly connected to the field device(s). It would be desirable to actually operate each device for this test, but the final details will be worked out in the approved CG\&A procedure.

\subsubsection{Validation Tests}

For final acceptance, operational tests shall be performed utilizing the final system and procedures. This test shall be a formal test conducted by Operations and will operate the complete SRS through a washing cycle.

\subsubsection{Mini-ATP}

A control system test shall be developed which can be performed at any time to verify that basic and essential control system functions are operating properly. The mini-ATP shall be a subset of a full system verification, so that it can be performed in less than a day - preferably less than an hour. The mini-ATP will be used as a minimum test following any maintenance or repair activities, following extended system shutdowns, or at any other time basic system integrity needs to be demonstrated.

\subsection{Training}

- The system simulation mode will support operator training by allowing the operator to actually operate the (simulated) system in a reasonably realistic mode. 


\subsection{Spares}

Spares will need to be provided for the Data Acquisition modules. A spare for the computer is not anticipated unless a non-standard configuration is required for mounting within panel C1167.

\subsection{Y2K Compliance}

The system timekeeping shall provide proper performance through the year 2000 transition.

\subsection{References}

- H-4-28240, "P\&ID, Sodium Removal System, IEM Cell, IDENT 89, SYS 41"

- H-4-28233, "Schematic Diagram, Sodium Removal System"

- CustomLine Control Products, Dwg 5306-4, "C1167 Panel Wiring Diagram"

- H-4-30807, "SRS Wiring Diagrams"

- H-4-30819, "SRS Wiring Diagrams"

- H-4-54237, “C11667 Wiring Diagrams"

- CustomLine Control Products, Dwg 5306-1, "C1167 Graphic Arrangement"

- HEDL-TI-75001, "FFTF Final Safety Analysis Report"

- DOE 6430.1A, General Design Criteria

- NUREG-700, Guidelines for Control Room Design Reviews 


\section{Attachment A: Existing SRS Interlocks}

Key to Implementation Code:

$\mathrm{SW}=$ computer software

$\mathrm{HW}=$ hardwired relays

$\mathrm{CB}=$ Circuit breaker (Administrative)

$\mathrm{EP}=$ Emergency Panel (Administrative)

\section{I-000: General: Timing of all MOV's}

Assure proper timing of all MOV operations, so that the motor is operated the proper time duration to achieve full stroke.

(New Implementation: SW)

\section{I-001: Auto Control of Blower B-001 and outlet valve SV-003}

Single control for B-001 and SV-003. Open valve first, and start blower only after the outlet valve is open.

(New Implementation: HW)

\section{I-002: Auto Control of Blower B-002 and outlet valve SV-004}

Single control for B-002 and SV-004. Open valve first, and start blower only after outlet valve is open.

(New Implementation: HW)

\section{I-003: Blower B-001 Auto Switchover}

Inhibit opening of HV-003 if $\mathrm{HV}-004$ is currently commanded to be open.

Inhibit opening of HV-003 unless HV-004 has been previously commanded to be open (even though it didn't open). Automatically close when blower B-001 is OFF, and is commanded to be OFF. Auto start of "Alt" blower on FSLL-7009, if HS-054 is in "Auto" position. (Note the above existing operation should be simplified.) (New Implementation: SW + EP)

\section{I-004: Blower B-002 Auto Switchover}

Inhibit opening of HV-004 if HV-003 is currently commanded to be open. Inhibit opening of HV-004 unless HV-003 has been previously commanded to be open (even though it didn't open). Automatically close when blower B-002 is OFF, and is commanded to be OFF. Auto start of "Alt" blower on FSLL-7009 if HS-054 is in AUTO position. (Note the above existing operation should be simplified.)

(New Implementation: $\mathrm{SW}+\mathrm{EP}$ )

\section{I-011: Shutoff Heater Q-011 on Low Flow}

Force Heater to OFF on low flow. (FSL-009)

(New Implementation: $\mathrm{SW}+\mathrm{CB}$ ) 


\section{I-020: Limit Dome Clamp Travel}

Shutoff Clamp open command when reach open limit switch

(New Implementation: SW + CB + EP)

\section{I-021: Latch PI-021 High and Low Alarms}

PI-021 LL and HH alarms latch, until pressure returns below $\mathrm{L}$ or $\mathrm{H}$ respectively.

For the LL alarm, however, there is a reset pushbutton for clearing the alarm between

these two limits. Alarms are used in I-119, I-161, I-175, I-251 and I-255

(New Implementation: SW)

\section{I-034/6: Prevent Water in Drying Loop}

Prevent opening of HV-034 or HV-036 if either HV-129 or HV-116 are open. Reference I-119/129 for symmetrical portion of interlock.

(New Implementation: SW + EP)

\section{I-101: Prevent Overfill of T101.}

Force SV101 closed on LSH-101

(New Implementation: SW + CB).

I-102: Protect Heater Q-101

Force heater Q-101 off if LSL-101 or PSH-101 or H1 power not applied.

(New Implementation: $\mathrm{SW}+\mathrm{CB}$ )

\section{I-113: Blower DP Protection}

Auto open of SV-113 on high Blower DP. Close on operator command.

(New Implementation: HW)

\section{I-119/129: Prevent Water in Drying Loop}

Force SV-119 and SV-129 to closed if either HV-034 or HV-036 are open, or if PSLL-21. Reference I-034/6 for symmetrical portion of interlock.

(New Implementation: $\mathrm{SW}+\mathrm{EP}$ ).

\section{I-145: T-102 High Level Protection}

Auto close of SV-145 on LSH-130 Also appears to be a manual override switch (reference sheet 29).

(New Implementation: $\mathrm{SW}+\mathrm{CB}+\mathrm{EP}$ )

\section{I-141 Prevent Water into T-100 if Dome Open}

Force SV-141 closed if dome clamp is open (ZS-020).

(New Implementation: $\mathrm{SW}+\mathrm{CB}+\mathrm{EP}$ )

\section{I-161: Isolate T-100 on High Pressure}

Force SV-161 closed if PSHH-021

(New Implementation: $\mathrm{SW}+\mathrm{CB}$ ) 


\section{I-175: Isolate T-101 on High Pressure}

Force SV-175 closed if PSH-101

(New Implementation: $\mathrm{SW}+\mathrm{CB}$ )

\section{I-251: Isolate T-101 on High Pressure in T100}

Force SV251 closed if PSHH-021. Previously, also closed on TSHH-021.

(New Implementation: $\mathrm{SW}+\mathrm{CB}$ )

\section{I-255: Isolate T-101 on High Pressure in T100}

Force SV-255 closed if PSHH-021 or TSHH-021.

(New Implementation: $\mathrm{SW}+\mathrm{CB}$ )

\section{I-613: Blower B-613 Outlet Valve Control}

Open/Close SV-613 when Blower B613 turned On/Off respectively.

(Implementation: $\mathrm{SW}+\mathrm{CB}$ ) 


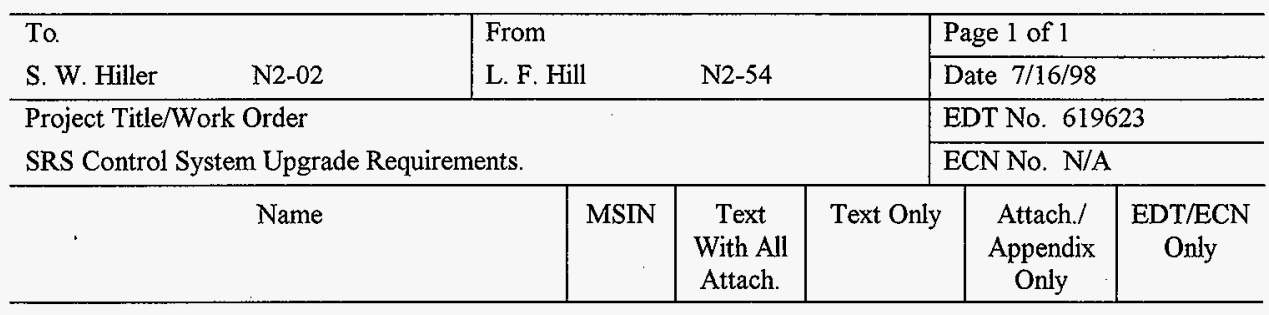

J. E. Baker

D. W. Brown

D. A. Crockett

S. V. Doebler

D. A. Gantt

S. Guttenberg

L. F. Hill

P. W. McGuiness

S. W. Hiller

J. N. Paglieri

J. E. Parker

G. N. Ruge

W. H. Taylor

SRS File

Central Files (orig +1 )
N2-57 X

N2-30 X

N2-30 $\mathrm{X}$

N2-34 X

$\mathrm{N} 2-13 \quad \mathrm{X}$

N2-53

$\mathrm{X}$

$\mathrm{N} 2-05 \quad \mathrm{X}$

N2-02 $\mathrm{X}$

N2-57 X

N2-11 X

N2-54 X

$\mathrm{N} 2-30 \quad \mathrm{X}$

$\mathrm{N} 2-54 \quad \mathrm{X}$

A3-89 $\mathrm{X}$ 